\title{
High-impact exercise in rats prior to and during suspension can prevent bone loss
}

\author{
G.R. Yanagihara ${ }^{1}$, A.G. Paiva ${ }^{1}$, G.A. Gasparini ${ }^{1}$, A.P. Macedo ${ }^{1}$, P.D. Frighetto ${ }^{2}$, J.B. Volpon ${ }^{1}$ \\ and A.C. Shimano ${ }^{1}$ \\ ${ }^{1}$ Laboratório de Bioengenharia, Departamento de Biomecânica, Medicina e Reabilitação do Aparelho Locomotor, \\ Faculdade de Medicina de Ribeirão Preto, Universidade de São Paulo, Ribeirão Preto, SP, Brasil \\ ${ }^{2}$ Instituto Federal de Educação, Ciência e Tecnologia de São Paulo, São Paulo, SP, Brasil
}

\begin{abstract}
High-impact exercise has been considered an important method for treating bone loss in osteopenic experimental models. In this study, we investigated the effects of osteopenia caused by inactivity in femora and tibiae of rats subjected to jump training using the rat tail suspension model. Eight-week-old female Wistar rats were divided into five groups ( $n=10$ each group): jump training for 2 weeks before suspension and training during 3 weeks of suspension; jump training for 2 weeks before suspension; jump training only during suspension; suspension without any training; and a control group. The exercise protocol consisted of 20 jumps/day, 5 days/week, with a jump height of $40 \mathrm{~cm}$. The bone mineral density of the femora and tibiae was measured by double energy X-ray absorptiometry and the same bones were evaluated by mechanical tests. Bone microarchitecture was evaluated by scanning electron microscopy. One-way ANOVA was used to compare groups. Significance was determined as $P<0.05$. Regarding bone mineral density, mechanical properties and bone microarchitecture, the beneficial effects were greater in the bones of animals subjected to pre-suspension training and subsequently to training during suspension, compared with the bones of animals subjected to pre-suspension training or to training during suspension. Our results indicate that a period of high impact exercise prior to tail suspension in rats can prevent the installation of osteopenia if there is also training during the tail suspension.
\end{abstract}

Key words: Bone; Mechanical properties; Bone mineral density; Scanning electron microscopy; Jump; Rats

\section{Introduction}

Osteoporotic fractures represent an important public health problem worldwide (1-3). Currently, it is estimated that 30 to $50 \%$ of women and 15 to $30 \%$ of men will suffer an osteoporotic fracture at some point in their life (1). In the United States, about 10 million Americans over the age of 50 have osteoporosis, while another 34 million have osteopenia. These conditions can lead to a diminished quality of life and increased risk of death. In Brazil, high rates of osteoporotic fractures have been reported by BRAZOS (Brazilian Osteoporosis Study) (4,5). The World Health Organization defines osteoporosis as the changes in bone micro-architecture resulting in a progressive loss of bone matrix quality, and decrease in the physical properties of the bone, such as bone mineral density (BMD) and elasticity $(6,7)$. Osteopenia is a reversible condition that precedes osteoporosis (7).

Several factors are helpful in the fight against bone loss, including a healthy life style, no smoking, use of therapeutic drugs and regular physical exercise $(8,9)$. The mechanical stress caused by physical activities is crucial for the structural and functional integrity of the skeletal system, since it increases bone density and mechanical strength $(1,10-15)$. For this reason, physical exercise has been referred as both a preventive and a therapeutic activity against bone loss and muscle atrophy. The increase of BMD $(1,2,9)$, and bone mass and strength $(10,16,17)$ by physical exercise have been shown in human and animal studies. One of the most effective physical activities in eliciting osteogenic response is the high impact exercise, as it causes a high tension and deformation rate in the bones $(1,13)$. Thus, jumping appears to promote superior bone formation compared with aerobic exercises (11,18-21).

The rat tail suspension test is an efficient model for inducing osteopenic changes secondary to physical hypoactivity (22-24). Some studies have used this model to investigate the effects of the jump exercise during the tail suspension period, in preventing the occurrence of osteopenia $(11,18,25)$. Furthermore, the jumping exercise during a remobilization period was evaluated as a treatment for previously established osteopenia (25). However, studies

Correspondence: G.R. Yanagihara: <gyangihara@usp.br> 
investigating jumping exercises before tail suspension and its effects in bone quality and the onset of osteopenia, were not found in the literature.

Therefore, the aim of this study was to evaluate whether training with jumps before and/or during the period of tail suspension of rats can prevent or minimize the bone loss caused by hypoactivity.

\section{Material and Methods}

This study was approved by the Ethics Committee on Animal Experimentation of the Faculdade de Medicina de Ribeirão Preto, Universidade de São Paulo, Brazil (\#2013/ 085). Procedures were performed in accordance with the International Guiding Principles for Biomedical Research Involving Animals (26) and with the Brazilian College of Animal Experimentation.

\section{Animals}

Eight-week-old female Wistar rats (190-210 g) were supplied by the vivarium of the Faculdade de Medicina de Ribeirão Preto, Universidade de São Paulo. Rats were housed in specific cages in a quiet environment and under normal conditions of controlled temperature $\left(22 \pm 2^{\circ} \mathrm{C}\right)$ and humidity (55-60\%). A 12-h light/dark cycle was maintained, and animals had access to standard rat chow and water ad libitum. Body weight was measured once a week. At the end of the experiment the rats were sacrificed with an overdose of ketamine chlorhydrate and xylazine chlorhydrate. Both femora and tibiae were then collected, cleaned of soft tissue and kept in a freezer.

\section{Experimental design}

The rats were divided into 5 groups ( $n=10$ per group), as follows: T/ST: jump training before suspension and training during suspension; T/S: jump training before suspension; U/ST: training only during suspension; U/S: suspension without any training, and $\mathrm{U} / \mathrm{U}$ : untrained and unrestricted in regular cages. The experimental design is shown in Figure 1.

\section{Tail suspension protocol}

The tail suspension procedure was performed in accordance with the recommendations by Holton and Globus (23). A strip was wrapped around the tail at $2 \mathrm{~cm}$ from its base, leaving its distal third free for circulation monitoring. The strip formed a loop to be connected to a swivel, which was connected to a transversal bar. The overhead trolley system allowed $360^{\circ}$ of rotation and was adjusted to keep the rat trunk at $30^{\circ}$ of inclination, thus permitting the animal to move around to reach for food and water, but not touching the cage floor or walls with the hind limbs (Figure 2). The rats were kept in suspension for 3 weeks. The rats submitted to training during the suspension period were removed from the suspension, submitted to jumping exercise and returned to the suspension thereafter.

\section{Jumping exercise protocol}

The jump training was performed by placing the rat inside a wooden box $\left(40 \times 40 \times 40 \mathrm{~cm}\right.$; Insight ${ }^{\mathbb{R}}$, Brazil). To elicit the first jumps the animals received an electrical stimulation delivered by a metal grid covering the box internal floor. The electrical discharge was controlled by the researcher. With the stimulus, the animal jumped and grasped the upper edge of the box with the forelimbs and climbed onto a board. The rat was then returned to the bottom of the box to repeat the procedure. After about 1 week the rats learned to jump as soon as they were placed in the box, so that the electrical stimulus was no longer necessary. The training protocol consisted of 20 jumps/day for 5 days a week. The training period before suspension had a duration of 2 weeks, and during suspension, 3 weeks. The initial jump height was $25 \mathrm{~cm}$, which was gradually increased to $40 \mathrm{~cm}$ by the end of the first week $(11,18)$.

\section{Bone densitometry}

The BMD of the left femora and tibiae was measured by a dual-energy X-ray absorptiometry densitometer (DXA; Hologic QDR ${ }^{\circledR}$, Discovery ${ }^{\mathrm{TM}}$, USA), with special QDR $^{\circledR}$ software for small animals, with high scanning resolution, following the proximal-distal direction. The analysis was performed in the femoral head, neck and trochanteric region and in the whole tibiae.

\section{Mechanical analysis}

The mechanical properties of maximum load $\left(L_{\max }\right)$ and stiffness (St) were determined by testing left bones to fracture in an universal testing machine $\left(E M I C{ }^{\mathbb{R}}, \mathrm{DL} 10000\right.$, Brazil) equipped with a load cell of $500 \mathrm{~N}$, and TESC software, version 13.4 (EMIC). For the left femur, flexocompression force was vertically applied to the femur head at a speed of $0.5 \mathrm{~mm} / \mathrm{min}$. Differently, the tibiae were tested by the three-point bending flexural test, with force applied at a speed of $1.0 \mathrm{~mm} / \mathrm{min}$ in the antero-posterior direction (Figure 3). In both tests, a $5 \mathrm{~N}$ preload was used for $30 \mathrm{~s}$.

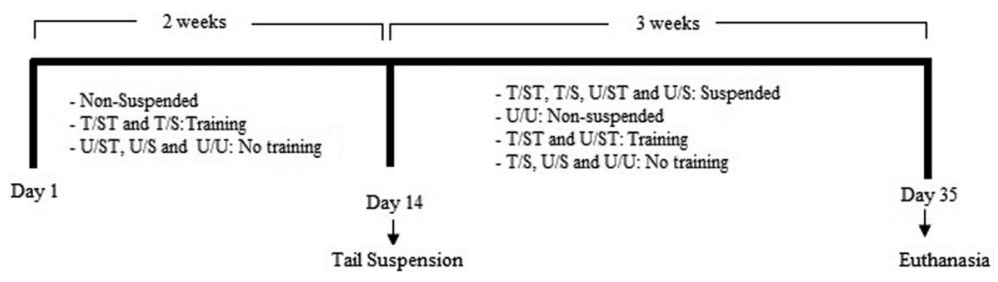

Figure 1. Experimental design. Rats were divided into 5 groups $(n=10)$ as follows: T/ST: jump training before suspension and training during suspension; T/S: jump training before suspension; U/ST: training only during suspension; U/S: suspension without any training, and $\mathrm{U} / \mathrm{U}$ : untrained and unrestricted in regular cages. 


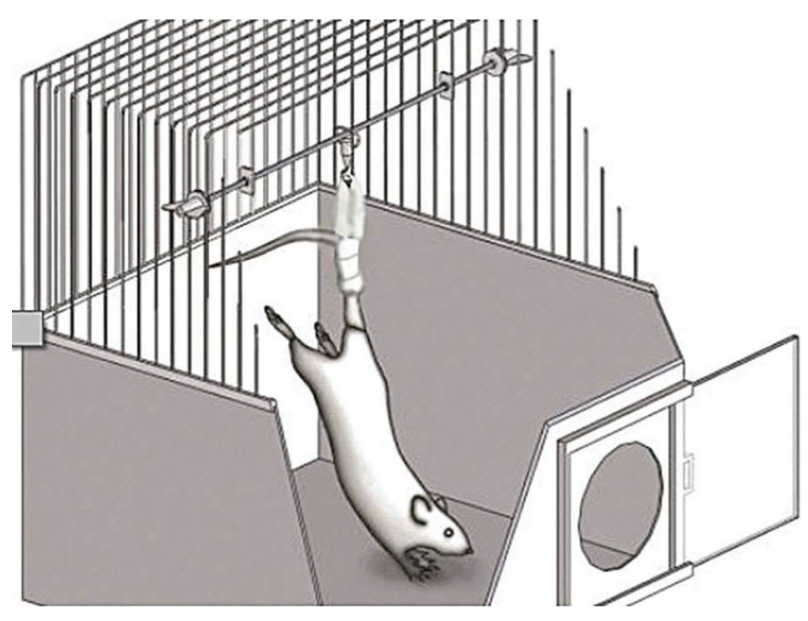

Figure 2. Schematic drawing of the rat tail suspension model.

\section{Scanning electron microscopy}

For the analysis by scanning electron microscopy (SEM), the right tibiae were kept in absolute ethyl alcohol for 5 days then cut (1-mm thick) in the coronal plane using an ISOMET $^{\circledR} 1000$ saw (Buehler, USA) (Figure 4). After cutting, the slices were attached to aluminum supports (stubs) with silver- and graphite-based conductive glue to improve the flow of electrons. The stubs were kept dry with silica gel (Synth ${ }^{\circledR}$ Labsynth, Brazil) and subsequently sputter-coated in gold, in a SCD 050 Sputter Coater (Bal-Tec ${ }^{\mathrm{TM}}$, Germany), for $350 \mathrm{~s}$. The stubs with the samples were then positioned in an Evo-MA10 electron microscope (Zeiss ${ }^{\mathrm{TM}}$, Germany). The images were obtained with $40 \times$ magnification and the trabecular spaces were analyzed qualitatively.

\section{Statistical analyses}

Statistical analyses were performed using SPSS 16.0 for Windows (IBM, USA). Normality of the data was tested with the Shapiro-Wilk test. Results were compared using ANOVA with the Tukey's post hoc test (parametric data) or KruskalWallis with Dunn's post hoc test (non-parametric data). The

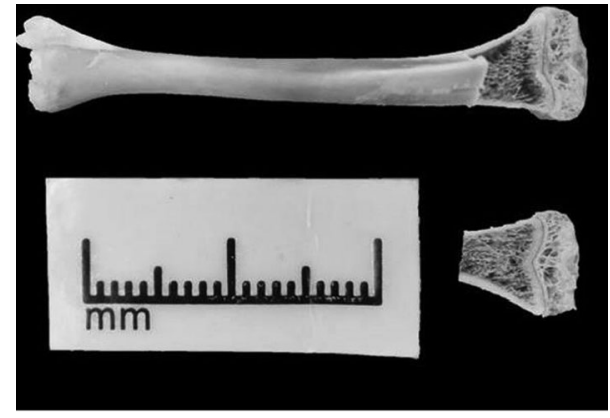

Figure 4. Preparation and analysis by scanning electron microscopy.

differences are reported as percentages. $P \leqslant 0.05$ was considered to be statistically significant.

\section{Results}

\section{Body mass}

At the beginning of the study, body mass was similar among the groups. After 4 weeks, the control group (U/U) had greater body mass than all suspended rats $(9.72 \%$ higher than T/ST, $14.02 \%$ higher than T/S, and $20.85 \%$ higher than $\mathrm{U} / \mathrm{S}, \mathrm{P}<0.001)$. The suspended group without training (U/S) had $9.21 \%$ lower body mass than T/ST, and $15.44 \%$ lower than U/ST $(P<0.001)$. At the end of the experiment the groups submitted to training (T/S, T/ST and U/ST) had body weight similar to the control group (U/U). The control group body weight was $13.06 \%$ higher than the suspended group without training $(\mathrm{U} / \mathrm{S})(\mathrm{P}<0.02)$ (Table 1).

\section{BMD}

Femora. Multivariate comparison showed significant differences in BMD of the femora between groups $\left(P<0.001 ; \eta_{p}{ }^{2}=0.725\right)$. The femora BMD of animals from T/S group was $12.05 \%$ lower than U/U, 10.83\% lower than T/ST, and $10.07 \%$ lower than U/ST $(P<0.01)$. The animals of the U/S group had BMD $16.66 \%$ lower than those

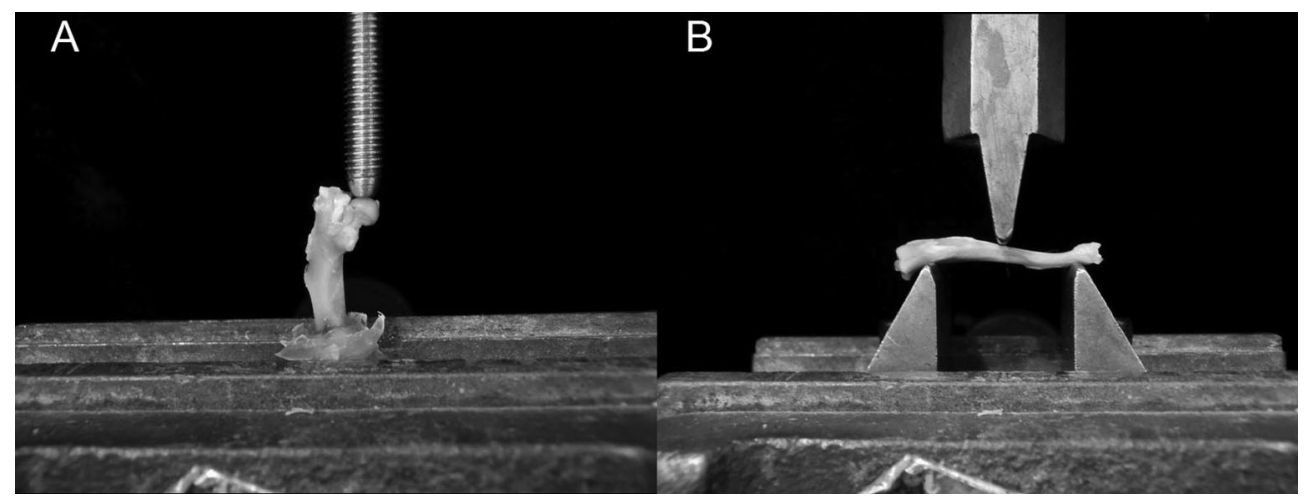

Figure 3. Mechanical testing. $A$, flexo-compression test of the femora and $B$, 3-point bending flexural test of the tibiae. 
Table 1. Body mass during experiment.

\begin{tabular}{llllll}
\hline & \multicolumn{5}{c}{ Body mass $(\mathrm{g})$} \\
\cline { 2 - 6 } & \multicolumn{1}{c}{$\mathrm{T} / \mathrm{ST}(\mathrm{n}=10)$} & $\mathrm{T} / \mathrm{S}(\mathrm{n}=10)$ & $\mathrm{U} / \mathrm{ST}(\mathrm{n}=10)$ & $\mathrm{U} / \mathrm{S}(\mathrm{n}=10)$ & $\mathrm{U} / \mathrm{U}(\mathrm{n}=10)$ \\
\hline Initial & $194.00 \pm 9.07$ & $197.78 \pm 7.55$ & $200.50 \pm 2.84$ & $196.50 \pm 7.84$ & $195.00 \pm 5.77$ \\
1st week & $229.00 \pm 10.75$ & $245.56 \pm 11.84$ & $242.00 \pm 4.38$ & $233.00 \pm 18.14$ & $239.50 \pm 20.47$ \\
2nd week & $269.00 \pm 12.65$ & $265.56 \pm 14.67$ & $281.50 \pm 18.11$ & $270.00 \pm 19.72$ & $277.50 \pm 22.52$ \\
3rd week & $275.50 \pm 17.71^{\mathrm{a}}$ & $281.11 \pm 9.61$ & $285.00 \pm 25.71$ & $279.00 \pm 28.85$ & $305.50 \pm 28.81$ \\
4th week & $298.50 \pm 17.80^{\mathrm{a}}$ & $287.22 \pm 31.73^{\mathrm{a}}$ & $299.00 \pm 24.59^{\mathrm{a}}$ & $271.00 \pm 24.13^{\mathrm{abc}}$ & $327.50 \pm 31.11$ \\
5th week & $315.00 \pm 21.08$ & $310.56 \pm 12.86$ & $320.50 \pm 32.18$ & $302.50 \pm 26.38^{\mathrm{a}}$ & $342.00 \pm 30.48$ \\
\hline
\end{tabular}

Data are reported as means $\pm \mathrm{SD}$. T/ST: trained/suspended +trained; T/S: trained/suspended; U/ST: untrained/suspended + trained; U/S: untrained/suspended; U/U: untrained/unrestricted. ${ }^{a} \mathrm{P}<0.05$ vs control (U/U group); ${ }^{\mathrm{b}} \mathrm{P}<0.01$ vs $\mathrm{T} / \mathrm{TS}$ group; ${ }^{\mathrm{C}} \mathrm{P}<0.01$ vs $\mathrm{U} / \mathrm{ST}$ group. ANOVA followed by Tukey's post-hoc test was used for statistical analysis.

of $\mathrm{U} / \mathrm{U}, 15.49 \%$ lower than T/ST, and $14.78 \%$ lower than U/ST $(P<0.01)$. There was no significant difference in BMD of the femora of the T/ST and U/ST groups compared to the control group $(P>0.05)$.

Tibiae. Multivariate comparison showed significant differences in tibiae BMD between groups $(P<0.0001$; $\left.\eta_{\mathrm{p}}{ }^{2}=0.725\right)$. The animals of group T/S had tibiae BMD $12.89 \%$ lower than $\mathrm{U} / \mathrm{U}, 7.98 \%$ lower than $\mathrm{T} / \mathrm{ST}$, and $9.00 \%$ lower than U/ST $(\mathrm{P}<0.01)$. The animals of the U/S group had tibiae BMD $20.50 \%$ lower than $U / U, 16.02 \%$ lower than T/ST, and $16.95 \%$ lower than U/ST $(P<0.01)$. There was no significant difference in tibiae BMD of the animals from the T/ST and U/ST groups compared to the control group ( $P>0.05$; Figure 5).

\section{Mechanical properties}

Femora. Multivariate comparison showed significant differences for $L_{\max }$ of the femora between groups $\left(P<0.001, \eta_{p}{ }^{2}=0.525\right)$. The $T / S$ group had $L_{\max }$ of femora $28.32 \%$ lower than $\mathrm{U} / \mathrm{U}$, and $29.02 \%$ lower than T/ST $(P<0.01)$. The $U / S$ group had $L_{\max }$ of femora $24.44 \%$ lower than $\mathrm{U} / \mathrm{U}$, and $24.96 \%$ lower than $\mathrm{T} / \mathrm{ST}(\mathrm{P}<0.01)$. The $L_{\max }$ of femora of the T/ST and U/ST groups were not statistically different to those of the control group $(P>0.05)$. The St of the femora was not significantly different between groups $\left(P>0.05, \eta_{p}{ }^{2}=0.118\right)$.

Tibiae. Multivariate comparison showed significant differences for $L_{\max }$ of the tibiae between the groups $\left(P<0.001, \eta_{p}{ }^{2}=0.548\right)$. The animals of $T / S$ had $L_{\max }$ $17.54 \%$ lower than U/U, 15.04\% lower than T/ST, and $19.53 \%$ lower than U/ST $(P<0.001)$. The animals of $U / S$ had $\mathrm{L}_{\max } 25.28 \%$ lower than $\mathrm{U} / \mathrm{U}, 22.91 \%$ lower than T/ST and $26.99 \%$ lower than U/ST $(P<0.001)$. The $L_{\max }$ and $S t$ of tibiae of the T/ST and U/ST groups were not statistically different to those of the control group $(P>0.05)$. Multivariate comparison showed significant differences for St of the tibiae between groups $\left(P<0.001, \eta_{p}{ }^{2}=0.438\right)$. The tibiae St was $31.73 \%$ lower in the animals of the T/S group than U/U, 22.34\% lower than T/ST and $24.90 \%$ lower than $\mathrm{U} / \mathrm{ST}(\mathrm{P}<0.01)$. The tibiae $\mathrm{St}$ of the $\mathrm{U} / \mathrm{S}$ group was
$25.28 \%$ lower than U/U, 22.72\% lower than T/ST, and $25.27 \%$ lower than U/ST $(\mathrm{P}<0.01)$ (Figure 6$)$.

\section{SEM}

Qualitative analysis of the SEM image showed that the T/ST and U/U groups had smaller spaces between trabeculae, indicating a higher bone microarchitecture quality compared with T/S, U/ST and U/S. The animals that were only suspended but not trained (U/S group) had the lowest bone microstructural quality (Figure 7).

\section{Discussion}

The main finding of this study was that the animals subjected to jumping exercises before and during tail

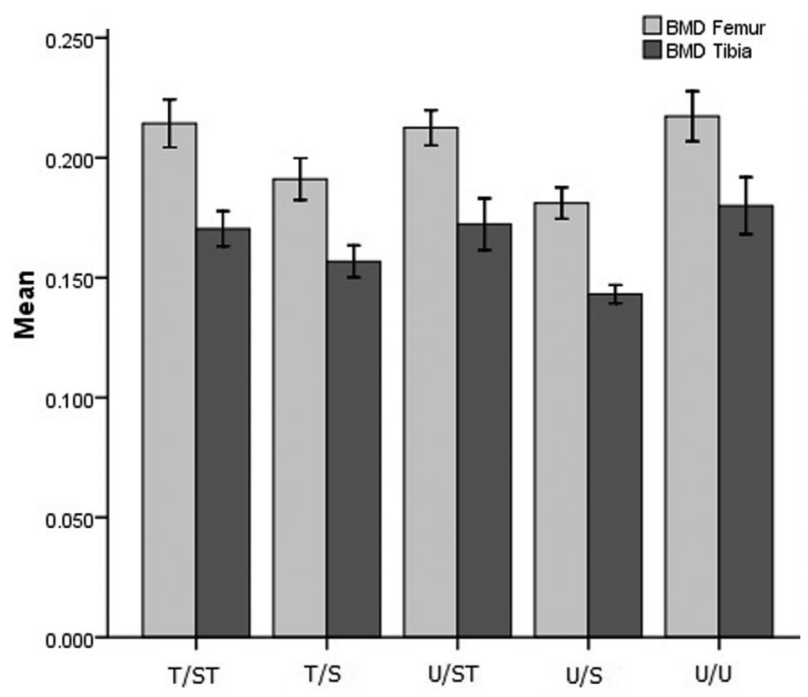

Figure 5. BMD (bone mineral density; $\mathrm{g} / \mathrm{cm}^{2}$ ) of the experimental groups. T/ST: trained/suspended + trained rats; T/S: trained/ suspended rats; U/ST: untrained/suspended + trained rats; U/S: untrained/suspended rats; U/U: untrained/unrestricted. Results are reported as mean and $95 \% \mathrm{Cl}$ for $n=10$ rats per group. 

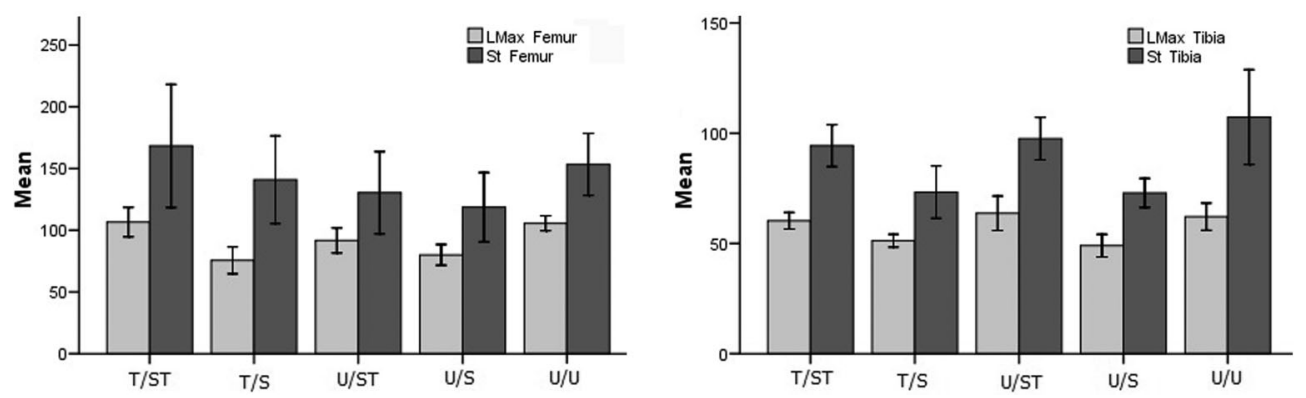

Figure 6. Mechanical properties of the femora (left pane/) and tibiae (right pane/). T/ST: trained/suspended + trained rats; T/S: trained/ suspended rats; U/ST: untrained/suspended + trained rats; U/S: untrained/suspended rats; U/U: untrained/unrestricted. $L_{\max }:$ maximum load $(\mathrm{N})$; St: stiffness $(\mathrm{N} / \mathrm{mm})$. Results are reported as mean and $95 \% \mathrm{Cl}$ for $\mathrm{n}=10$ rats per group.

suspension resulted in an overall higher bone quality when compared with animals, which were submitted to jumping either before or during suspension.

In 1979, to simulate bone changes induced by microgravity as experienced by astronauts or animals in space flights, Morey ER (27) developed a model in which the hind limbs of rodents were suspended by the tail. This model, now a well-accepted method to evaluate osteopenia caused by disuse/hypoactivity $(11,18,25,28)$, allows the development of studies that would not be feasible in human subjects, specially because of ethical aspects and the required long follow-up. Loss of body mass is an important indicator of stress in this model. According to Morey-Holton and Globus (23), a limit of $10 \%$ weight loss in $24 \mathrm{~h}$ is acceptable, which must be recovered within 2 days. In our study, body mass increased each week in all groups, which is consistent with the recommendations by Morey-Holton and Globus (23). Suspended rats had a smaller and slower body mass gain than unrestricted rats. Furthermore, we observed that jump training prevented

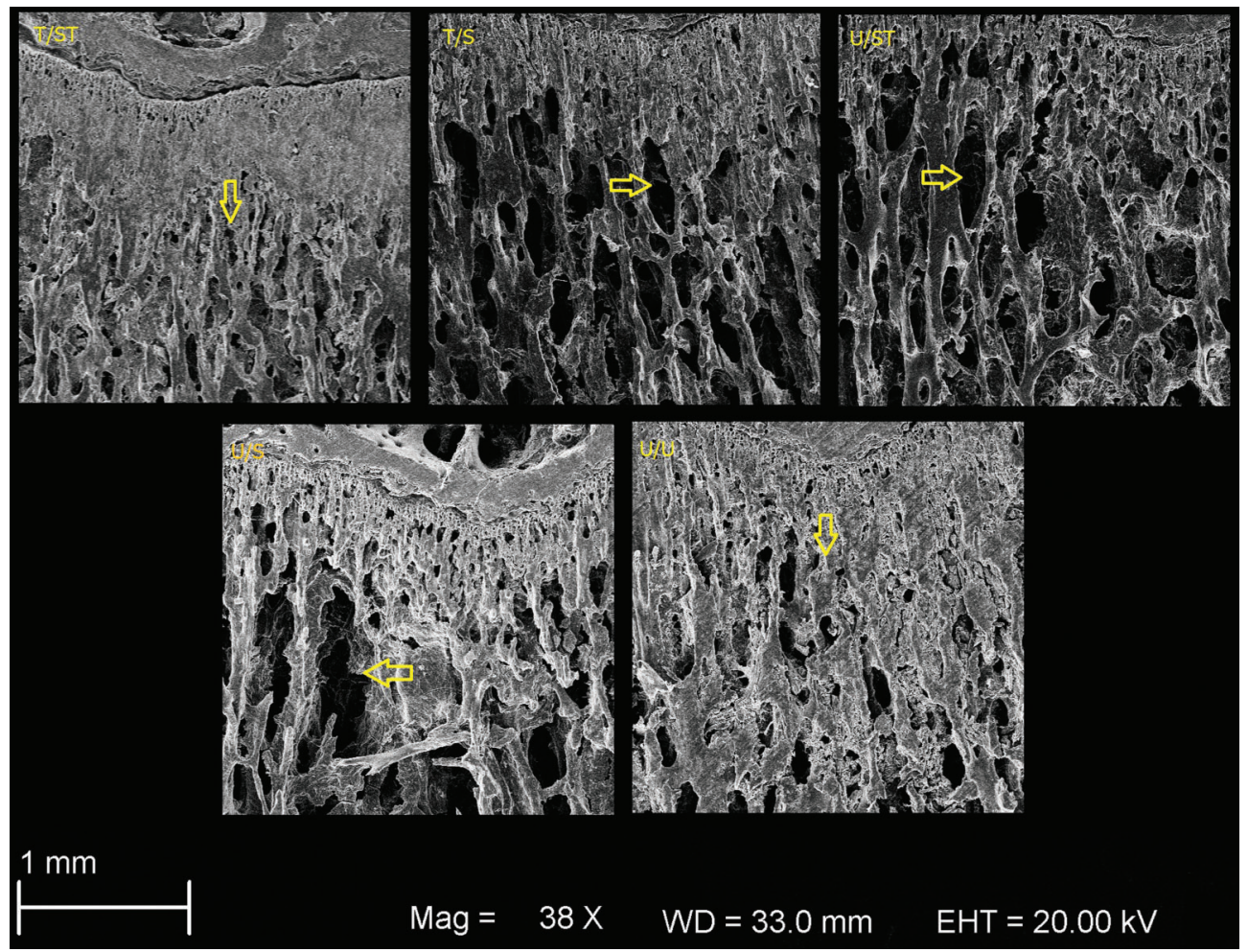

Figure 7. Scanning electron microscopy showing comparative bone micro-architecture. Arrows indicate trabecular space. T/ST: trained/ suspended + trained rats; T/S: trained/suspended rats; U/ST: untrained/suspended + trained rats; U/S: untrained/suspended rats; U/U: untrained/unrestricted. 
loss of body mass. These findings are in agreement with other studies $(18,23,29,30)$.

Physical training is known to counteract osteopenia caused by disuse $(8,18,31)$. The positive effects of exercise on BMD, added to the other known benefits of exercise, such as a balanced and improved muscle function, can reduce the incidence of fractures by up to $50 \%(31,32)$. In addition, training with jumps has been shown to be effective for treatment as well as prevention of bone osteopenia in rats $(13,18,25,33-34)$.

Continuous training seems to be necessary for maintaining bone quality (35-37). However, there are reports in which the beneficial effects promoted by high-impact training can be maintained after a non-training period of up to 6 months $(10,38)$. The inclusion of a training session before tail suspension in the current study was based on the hypothesis that the acquired benefits could minimize the deleterious effects caused by hypoactivity.

We found that tail suspension caused deterioration in bone quality, which is in accordance with several authors $(11,18,25)$ who found a decrease of mechanical properties such as stiffness, resilience and maximum load limit in adult rats subjected to tail suspension. On the other hand, training with jumps improved BMD and femoral strength. Similar results were found in the studies by Ju et al. in 2012 (11) and 2013 (18), in which the suspended rats had decreased bone mass, and suspended rats trained with jumping exercises showed bone mass similar to those of the control group. However, in these studies rats did not have any exercise prior to suspension. In the current study, the positive findings in bone quality of the animals trained only during suspension (U/ST) compared to the suspended group that never trained (U/S) suggest that this protocol might be also effective in preventing osteopenia.

Although many studies use BMD as a measure of bone fragility, currently it has been reported that up to $80 \%$ of low-trauma fractures occur in individuals without osteoporosis $(1,33)$, indicating that bone densitometry by DXA may not be sufficient to obtain an accurate measure of bone strength. Another disadvantage of bone densitometry, is the variation in bone mass and geometry depending on the area analyzed. A larger cross section of the bone can lead to a higher measure of bone strength, without real changes in BMD. Furthermore, trabecular micro-architecture of bones can adapt to force loading, but

\section{References}

1. Nikander R, Sievanen H, Heinonen A, Daly RM, Uusi-Rasi K, Kannus P. Targeted exercise against osteoporosis: A systematic review and meta-analysis for optimising bone strength throughout life. BMC Med 2010; 8: 47, doi: 10.1186/17417015-8-47.

2. Cummings SR, Melton LJ. Epidemiology and outcomes of osteoporotic fractures. Lancet 2002; 359: 1761-1767, doi: 10.1016/S0140-6736(02)08657-9. most imaging techniques are still limited in their measuring accuracy to detect these changes. For these reasons, the effects of physical exercise on bone micro-architecture are not yet fully understood (1). As far as we know, this is the first study in this line of research that used SEM analysis.

The results found for BMD and mechanical analysis are consistent with each other and confirmed by electron microscopy. The trabecular space was larger in suspended animals compared to control, and smaller in trained animals compared to non-trained animals, supporting the positive results of exercise training before and during tail suspension. Ju et al. in 2013 (18) observed architectural deterioration in the trabecular network of the femora mainly attributed to the reduced number of trabeculae in suspended rats, assessed by computerized microtomography. This deterioration was not found in animals trained with jumping exercises.

The duration of the jump training protocol reported in the literature varies: 24 weeks $(39), 8$ weeks $(10,33)$, 5 weeks (25), 3 weeks (18), and 1 week (15). In our study, a total training period of 5 weeks was set, with 2 weeks of pre-suspension training and 3 weeks of training during suspension.

Although pre-suspension training alone demonstrated higher values than absence of training, the difference was non-significant. This suggests that a longer period of presuspension training by itself might generate positive effects on bone after suspension. Therefore, further studies with different exercise protocols, especially regarding duration, are necessary to better understand the effects of physical training followed by a period of hypoactivity.

In conclusion, our findings showed that tail suspension reduced BMD and mechanical properties of the femora and tibiae of rats, and increased trabecular space. Pre-suspension jump training alone was not effective to prevent bone loss due to disuse, but jump training prior to and during tail suspension was beneficial to the bone, keeping the physical properties unchanged.

\section{Acknowledgments}

The primary financial support for this research project was from the São Paulo Research Foundation (FAPESP, \#2012/473678-8) and Coordination for the Improvement of Higher Education Personnel (CAPES).
3. Kannus P, Niemi S, Parkkari J, Palvanen M, Vuori I, Jarvinen M. Nationwide decline in incidence of hip fracture. J Bone Miner Res 2006; 21: 1836-1838, doi: 10.1359/JBMR.060815.

4. Pinheiro MM, Ciconelli RM, Martini LA, Ferraz MB. Clinical risk factors for osteoporotic fractures in Brazilian women and men: the Brazilian Osteoporosis Study (BRAZOS). Osteoporos Int 2009; 20: 399-408, doi: 10.1007/s00198-0080680-5. 
5. Pinheiro MM, Ciconelli RM, Jacques NO, Genaro PS, Martini LA, Ferraz MB. O impacto da osteoporose no Brasil: dados regionais das fraturas em homens e mulheres adultos - The Brazilian Osteoporosis Study (BRAZOS). Rev Bras Reumatol 2010; 50: 113-127.

6. Bloomfield SA, Allen MR, Hogan HA, Delp MD. Site- and compartment-specific changes in bone with hindlimb unloading in mature adult rats. Bone 2002; 31: 149-157, doi: 10.1016/S8756-3282(02)00785-8.

7. Kanis JA, McCloskey EV, Johansson H, Oden A, Melton LJ III, Khaltaev N. A reference standard for the description of osteoporosis. Bone 2008; 42: 467-475, doi: 10.1016/j.bone. 2007.11.001.

8. Cavanagh PR, Licata AA, Rice AJ. Exercise and pharmacological countermeasures for bone loss during long-duration space flight. Gravit Space Biol Bull 2005; 18: 39-58.

9. Norman TL, Bradley-Popovich G, Clovis N, Cutlip RG, Bryner RW. Aerobic exercise as a countermeasure for microgravity-induced bone loss and muscle atrophy in a rat hindlimb suspension model. Aviat Space Environ Med 2000; 71: 593-598.

10. Honda A, Sogo N, Nagasawa S, Shimizu T, Umemura Y. Highimpact exercise strengthens bone in osteopenic ovariectomized rats with the same outcome as Sham rats. J Appl Physiol 2003; 95: 1032-1037, doi: 10.1152/japplphysiol.00781.2002.

11. Ju YI, Sone T, Ohnaru K, Choi HJ, Fukunaga M. Differential effects of jump versus running exercise on trabecular architecture during remobilization after suspension-induced osteopenia in growing rats. J Appl Physiol 2012; 112: 766-772, doi: 10.1152/japplphysiol.01219.2011.

12. Lespessailles E, Gadois C, Lemineur G, Do-Huu JP, Benhamou $\mathrm{L}$. Bone texture analysis on direct digital radiographic images: precision study and relationship with bone mineral density at the os calcis. Calcif Tissue Int 2007; 80: 97-102, doi: 10.1007/s00223-006-0216-y.

13. Umemura $Y$, Nagasawa $S$, Honda A. High-impact exercise frequency per week or day for osteogenic response in rats. J Bone Miner Metab 2008; 26: 456-460, doi: 10.1007/ s00774-007-0848-7.

14. Chang TK, Huang $\mathrm{CH}$, Huang $\mathrm{CH}$, Chen $\mathrm{HC}$, Cheng $\mathrm{CK}$. The influence of long-term treadmill exercise on bone mass and articular cartilage in ovariectomized rats. BMC Musculoskelet Disord 2010; 11: 185, doi: 10.1186/1471-2474-11-185.

15. Nagasawa S, Honda A, Sogo N, Umemura Y. Effects of lowrepetition jump exercise on osteogenic response in rats. $J$ Bone Miner Metab 2008; 26: 226-230, doi: 10.1007/s00774-0070812-6.

16. Heinonen A, Oja P, Sievanen H, Pasanen M, Vuori I. Effect of two training regimens on bone mineral density in healthy perimenopausal women: a randomized controlled trial. J Bone Miner Res 1998; 13: 483-490, doi: 10.1359/jbmr.1998.13.3.483.

17. Iwamoto J, Takeda $\mathrm{T}$, Ichimura S. Effects of exercise on bone mineral density in mature osteopenic rats. $J$ Bone Miner Res 1998; 13: 1308-1317, doi: 10.1359/jbmr.1998.13.8.1308.

18. Ju YI, Sone T, Ohnaru K, Choi HJ, Choi KA, Fukunaga M. Jump exercise during hindlimb unloading protect against the deterioration of trabecular bone microarchitecture in growing young rats. Springerplus 2013; 2: 35, doi: 10.1186/21931801-2-35.

19. McKay HA, MacLean L, Petit M, Kelvie-O'Brien K, Janssen $\mathrm{P}$, Beck T, et al. "Bounce at the Bell": a novel program of short bouts of exercise improves proximal femur bone mass in early pubertal children. Br J Sports Med 2005; 39: 521-526, doi: 10.1136/bjsm.2004.014266.

20. Kato T, Terashima T, Yamashita T, Hatanaka Y, Honda A, Umemura Y. Effect of low-repetition jump training on bone mineral density in young women. J Appl Physiol 2006; 100: 839-843, doi: 10.1152/japplphysiol.00666.2005.

21. Umemura $Y$, Ishiko T, Yamauchi T, Kurono M, Mashiko S. Five jumps per day increase bone mass and breaking force in rats. J Bone Miner Res 1997; 12: 1480-1485.

22. Hefferan TE, Evans GL, Lotinun S, Zhang M, Morey-Holton E, Turner RT. Effect of gender on bone turnover in adult rats during simulated weightlessness. J Appl Physiol 2003; 95: 1775-1780, doi: 10.1152/japplphysiol.00455.2002.

23. Morey-Holton ER, Globus RK. Hindlimb unloading rodent model: technical aspects. J Appl Physiol 2002; 92: 1367-1377, doi: 10.1152/japplphysiol.00969.2001.

24. Widrick JJ, Maddalozzo GF, Hu H, Herron JC, Iwaniec UT, Turner RT. Detrimental effects of reloading recovery on force, shortening velocity, and power of soleus muscles from hindlimb-unloaded rats. Am J Physiol Regul Integr Comp Physiol 2008; 295: R1585-R1592, doi: 10.1152/ajpregu. 00045.2008 .

25. Ju YI, Sone T, Okamoto T, Fukunaga M. Jump exercise during remobilization restores integrity of the trabecular architecture after tail suspension in young rats. J Appl Physiol 2008; 104: 1594-1600, doi: 10.1152/japplphysiol. 01004.2007.

26. Council for International Organizations of Medical Sciences. International guiding principles for biomedical research involving animals. Washington DC: The National Academie Press; 1985.

27. Morey ER. Spaceflight and bone turnover - correlation with a new rat model of weightlessness. Bioscience 1979; 29: 168-172, doi: $10.2307 / 1307797$.

28. Falcai MJ, Louzada MJ, de Paula FJ, Okubo R, Volpon JB. A modified technique of rat tail suspension for longer periods of observation. Aviat Space Environ Med 2012; 83: 1176-1180, doi: 10.3357/ASEM.3248.2012.

29. Silva AV, Volpon JB. Modelo de suspensão pela cauda e seu efeito em algumas propriedades mecânicas do osso do rato. Acta Ortop Bras 2004; 12: 22-31, doi: 10.1590/S141378522004000100004

30. Hatori M, Hasegawa A, Adachi H, Shinozaki A, Hayashi R, Okano $\mathrm{H}$, et al. The effects of walking at the anaerobic threshold level on vertebral bone loss in postmenopausal women. Calcif Tissue Int 1993; 52: 411-414, doi: $10.1007 /$ BF00571327.

31. Newhall KM, Rodnick KJ, van der Meulen MC, Carter DR, Marcus R. Effects of voluntary exercise on bone mineral content in rats. J Bone Miner Res 1991; 6: 289-296, doi: 10.1002/jbmr.5650060311.

32. Kemmler W, von Stengel S, Engelke K, Haberle L, Kalender WA. Exercise effects on bone mineral density, falls, coronary risk factors, and health care costs in older women: the randomized controlled senior fitness and prevention (SEFIP) study. Arch Intern Med 2010; 170: 179-185, doi: 10.1001/ archinternmed.2009.499.

33. Honda A, Sogo N, Nagasawa S, Kato T, Umemura Y. Bones benefits gained by jump training are preserved after detraining in young and adult rats. J Appl Physiol 2008; 105: 849-853, doi: 10.1152/japplphysiol.00902.2007. 
34. Bassey EJ, Ramsdale SJ. Increase in femoral bone density in young women following high-impact exercise. Osteoporos Int 1994; 4: 72-75, doi: 10.1007/BF01623226.

35. Jarvinen TL, Kannus $P$, Sievanen $H$. Have the DXA-based exercise studies seriously underestimated the effects of mechanical loading on bone? J Bone Miner Res 1999; 14: 1634-1635.

36. Pajamaki I, Kannus P, Vuohelainen T, Sievanen H, Tuukkanen $\mathrm{J}$, Jarvinen $\mathrm{M}$, et al. The bone gain induced by exercise in puberty is not preserved through a virtually life-long deconditioning: a randomized controlled experimental study in male rats. J Bone Miner Res 2003; 18: 544-552, doi: 10.1359/jbmr.2003. 18.3.544.
37. Wu J, Wang XX, Higuchi M, Yamada K, Ishimi Y. High bone mass gained by exercise in growing male mice is increased by subsequent reduced exercise. J Appl Physiol 2004; 97: 806-810, doi: 10.1152/japplphysiol.01169.2003.

38. Warden SJ, Fuchs RK, Castillo AB, Nelson IR, Turner CH. Exercise when young provides lifelong benefits to bone structure and strength. J Bone Miner Res 2007; 22: 251-259, doi: 10.1359/jbmr.061107.

39. Ooi FK, Singh R, Singh HJ. Changes in bone turnover markers and bone mass with reducing levels of jumping exercise regimens in female rats. Asian J Sports Med 2012; 3: 225-232. 